\title{
A GRONWALL INEQUALITY AND THE CAUCHY-TYPE PROBLEM BY MEANS OF $\psi$-HILFER OPERATOR
}

\author{
José Vanterler da Costa Sousa and Edmundo CAPElas de Oliveira
}

Abstract. In this paper, we propose a generalized Gronwall inequality through the fractional integral with respect to another function. The Cauchy-type problem for a nonlinear differential equation involving the $\psi$-Hilfer fractional derivative and the existence and uniqueness of solutions are discussed. Finally, through generalized Gronwall inequality, we prove the continuous dependence of data on the Cauchy-type problem.

Mathematics subject classification (2010): 26A33, 36A08, 34A12, 34A40.

Keywords and phrases: $\psi$-Hilfer fractional derivative, Cauchy-type problem, existence and uniqueness, continuous dependence, generalized Gronwall inequality.

\section{REFERENCES}

[1] R. Almeida, A Caputo fractional derivative of a function with respect to another function, Commun. Nonl. Sci. Numer. Simulat. 44 (2017) 460-481.

[2] R. Almeida, A Gronwall inequality for a general Caputo fractional operator, Math. Inequal. Appl. 20(4) (2017) 1089-1105.

[3] M. Ashyraliyev, On Gronwall's type integral inequalities with singular kernels, Filomat 31 (4) (2017) 1041-1049.

[4] R. Courant, Differential and integral calculus, Vol. 2, John Wiley \& Sons, New York, 2011.

[5] D. Dhaigude, S. P. Bhairat, Existence and uniqueness of solution of Cauchy-type problem for Hilfer fractional differential equations, (2017) arXiv:1704.02174.

[6] S. S. Dr AGOMIR, Some Gronwall Type Inequalities and Applications, RGMIA Monographs, Victoria University, 2003.

[7] K. M. FURATI, M. KASSIM, Existence and uniqueness for a problem involving Hilfer fractional derivative, Comput. Math. Appl. 64 (6) (2012) 1616-1626.

[8] Z. Gong, D. QIAn, C. Li, P. Guo, On the Hadamard type fractional differential system, Frac. Dyn. Control, (2012) 159-171.

[9] D. Guyomar, B. Ducharne, G. Sebald, D. Audiger, Fractional derivative operators for modeling the dynamic polarization behavior as a function of frequency and electric field amplitude, IEEE transactions on ultrasonics, ferro electrics, and frequency control, 56 (3) (2009) 437-443.

[10] R. Herrmann, Fractional Calculus: An Introduction for Physicists, World Scientific Publishing Company, Singapore, 2011.

[11] R. Hilfer, Y. LuChKo, Z. TOMOVS KI, Operational method for the solution of fractional differential equations with generalized Riemann-Liouville fractional derivatives, Fract. Calc. Appl. Anal. 12 (3) (2009) 299-318.

[12] A. A. Kilbas, H. M. SRivastava, J. J. Trujillo, Theory and Applications of Fractional Differential Equations, North-Holland Mathematics Studies, Elsevier, Amsterdam, 2006.

[13] A. A. KILBAS, S. A. MARZAN, Nonlinear differential equations with the Caputo fractional derivative in the space of continuously differentiable functions, Diff. Equ. 41 (1) (2005) 84-89.

[14] A. Kilbas, S. Marzan, Cauchy problem for differential equation with Caputo derivative, Fract. Cal. Appl. Anal., 7 (3) (2004) 297p-321p.

[15] E. L. LimA, Real Analysis (in portuguese), Rio de Janeiro: Instituto de Matemática Pura e Aplicada, CNPq, 2004. 
[16] J. Nanware, D. Dhaigude, Existence and uniqueness of solution of Riemann-Liouville fractional differential equations with integral boundary conditions, Int. J. Nonlinear Sci., 14 (4) (2012) 410-415.

[17] D. S. Oliveira, E. Capelas de Oliveira, Hilfer-Katugampola fractional derivatives, Comput. Appl. Math., 37 (2018) 3672-3690.

[18] E. CAPelas de Oliveira, J. VANTERler Da C. Sousa, Ulam-Hyers-Rassias stability for a class of fractional integro-differential equations, Results in Math., 73 (3) (2018) 111.

[19] S. G. Samko, A. A. Kilbas, O. I. Marichev, Fractional integrals and derivatives, Theory and Applications, Gordon and Breach, Yverdon, 1993.

[20] J. Vanterler Da C. Sousa, E. Capelas de Oliveira, On the $\psi$-Hilfer fractional derivative, Commun. Nonlinear Sci. Numer. Simul. 60 (2018) 72-91.

[21] J. Vanterler da C. Sousa, E. Capelas de Oliveira, Fractional order pseudoparabolic partial differential equation: Ulam-Hyers stability, Bull. Braz. Math. Soc., New Series, (2018), https://doi.org/10.1007/s00574-018-0112-x.

[22] J. Vanterler da C. Sousa, D. Santos Oliveira, E. Capelas de Oliveira, On the existence and stability for non-instantaneous impulsive fractional integrodifferential equation, Math. Meth. Appl. Sci., (Accepted for publication) (2018).

[23] J. Vanterler Da C. Sousa, E. CAPelas de Oliveira, Existence, uniqueness, estimation and continuous dependence of the solutions of a nonlinear integral and an integrodifferential equations of fractional order, arXiv: 1806.01441, (2018).

[24] J. Vanterler da C. Sousa, E. Capelas de Oliveira, Ulam-Hyers stability of a nonlinear fractional Volterra integro-differential equation, Appl. Math. Lett. 81 (2018) 50-56.

[25] J. Vanterler da C. Sousa, Kishor D. Kucche, E. Capelas de Oliveira, Stability of $\psi$ Hilfer impulsive fractional differential equations, Appl. Math. Lett. 88 (2019) 73-80.

[26] J. VAnterler Da C. Sous A, E. Capelas de Oliveira, On the Ulam-Hyers-Rassias stability for nonlinear fractional differential equations using the $\psi$-Hilfer operator, J. Fixed Point Theory Appl. 20 (3) (2018) 96.

[27] J. Vanterler da C. Sousa, D. Santos Oliveira, E. Capelas de Oliveira, A note on the mild solutions of Hilfer impulsive fractional differential equations, arXiv: 1811.09256, (2018).

[28] F.-F. WAng, D.-Y. Chen, X.-G. Zhang, Y. Wu, The existence and uniqueness theorem of the solution to a class of nonlinear fractional order system with time delay, Appl. Math. Lett. 53 (2016) $45-51$.

[29] J. WANG, Y. ZHOU, Existence of mild solutions for fractional delay evolution systems, Appl. Math. Comput. 218 (2) (2011) 357-367.

[30] R. Wong, Asymptotic Approximations of Integrals, SIAM. Philadelphia, 2001.

[31] H. YE, J. GAO, Y. DING, A generalized Gronwall inequality and its application to a fractional differential equation, J. Math. Anal. Appl. 328 (2) (2007) 1075-1081. 